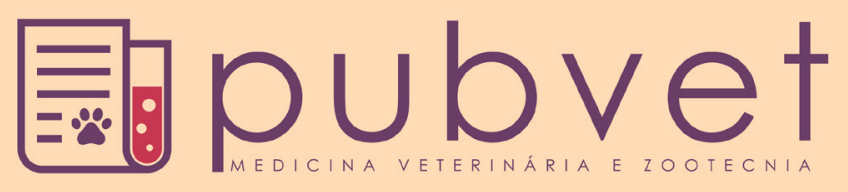

ISSN $1982-1263$

HTTP://DX.DOI.ORG/10.22256/PUBVET.V11N4.320-326

\title{
O comércio do camarão da Amazônia (Macrobrachium amazonicum) na cidade de Breves - Pará - Brasil
}

Fabricio Nilo Lima da Silva ${ }^{1 *}$, Fernanda Reis da Silva ${ }^{2}$, Tiago Paixão Mangas ${ }^{1}$, Luã Caldas de Oliveira ${ }^{1}$, Antonia Rafaela Gonçalves Macedo ${ }^{3}$, Luciano Ramos de Medeiros ${ }^{4}$, Carlos Alberto Martins Cordeiro ${ }^{5}$

${ }^{I}$ Professor do Instituto Federal de Educação, Ciência e Tecnologia do Pará, IFPA Campus Breves, Pará, Brasil. E-mail: tiago.mangas@ifpa.edu.br; lua.oliveira@ifpa.edu.br;

${ }^{2}$ Discente do Curso de Criador de Peixes em Viveiros Escavados do Instituto Federal de Educação, Ciência e Tecnologia do Pará, IFPA Campus Breves, Pará, Brasil. E-mail: fernandareissilva@live.com;

${ }^{3}$ Doutoranda do Programa de Pós-Graduação em Ciência Animal pela Universidade Federal do Pará, UFPA Campus Castanhal, Pará, Brasil.E-mail: agmaquicultura@hotmail.com;

${ }^{4}$ Mestre em Desenvolvimento Rural e Gestão de Empreendimentos Agroalimentares pelo Instituto Federal de Educação, Ciência e Tecnologia do Pará, IFPA Campus Castanhal, Pará, Brasil.E-mail: lucianomedeiros_ses@hotmail.com;

${ }^{5}$ Professor da Universidade Federal do Pará, UFPA Campus Bragança, Pará, Brasil. E-mail: camcordeiro2006@gmail.com.

*Autor para correspondência, E-mail:_fabricionilo@hotmail.com

RESUMO. Objetivou-se traçar o perfil dos vendedores e da comercialização durante a venda do camarão da Amazônia (Macrobrachium amazonicum, Heller, 1862) na feira livre da cidade de Breves, localizada na Ilha do Marajó, estado do Pará/Brasil. A pesquisa foi realizada no mês de setembro de 2016 em cinco pontos. Foi aplicado um questionário semiestruturado com questões sobre: gênero, idade, naturalidade, estado civil, nível de escolaridade, tempo de trabalho com camarão, atividade principal de renda, bem como, o comércio do camarão, tamanhos de venda dos animais, procedência desse crustáceo, dentre outros dados relevantes para traçar o perfil. Evidencia-se a predominância do sexo masculino e homens casados, onde a maioria é natural de Breves. Muitos possuem apenas ensino fundamental incompleto e comercializam os camarões in natura e salgado, sendo vendidos em três tamanhos: pequeno, médio e grande. Conclui-se, que a venda na feira livre de Breves na Amazônia, possui um grande potencial de crescimento para fortalecer a economia local com a venda de Macrobrachium amazonicum.

Palavras chave: Proteína, Amazônia, crustáceo

\section{The trade of the Amazonian shrimp (Macrobrachium amazonicum) in the city of Breves - Pará - Brazil}

\begin{abstract}
The objective of this work was to describe the profile of the sellers and the commercialization during the sale of the Amazonian shrimp (Macrobrachium amazonicum, Heller, 1862) at the Breves fair, located in Marajó Island, Pará State, Brazil. The survey was conducted in September 2016 in five points. A semi-structured questionnaire was applied with questions about: gender, age, naturalness, marital status, schooling level, working time with shrimp, main income activity, as well as shrimp trade, sale sizes of the animals, origin of this crustacean among other relevant data to draw the profile. It is evidenced the predominance of males and married men, where the majority is natural of Breves. Many have only incomplete elementary education and market fresh and salty shrimp, being sold in three sizes: small, medium and large. The sale in the free fair of Breves in the Amazon, has a great potential of growth to strengthen the local economy with the sale of Macrobrachium amazonicum.
\end{abstract}

Keywords: Protein, amazonian, crustacean 


\title{
El comercio del camarón de la Amazônia (Macrobrachium amazonicum) na cidade de Breves - Pará - Brasil
}

\begin{abstract}
RESUMEN. Este estudio tuvo como objetivo perfilar los vendedores y la comercialización durante la venta de camarones de la Amazonía (Macrobrachium amazonicum, Heller, 1862) en el mercado libre de la ciudad de Breves, localizada en la isla de Marajó, Pará / Brasil. La investigación se llevó a cabo en septiembre de 2016 en cinco puntos. Fue aplicado un cuestionario semiestructurado con preguntas sobre: género, edad, nacionalidad, estado civil, nivel de escolaridad, tiempo de trabajo con camarones, actividad principal de renta, así como el comercio del camarón, tamaños de venta de los animales, origen de este crustáceo entre otros datos relevantes para trazar el perfil. Se destaca la predominancia del sexo masculino y hombres casados, de los cuales la mayoría son naturales de Breves. Muchos sólo han completado la educación primaria y comercializan los camarones in natura y salado, siendo vendidos en tres tamaños: pequeño, mediano y grande. Se concluyó que la venta en el mercado libre de Breves en la Amazonia, posee un gran potencial de crecimiento para fortalecer la economía local con la venta de Macrobrachium amazonicum.
\end{abstract}

Palabras clave: Proteína, Amazonia, crustáceo

\section{Introdução}

O pescado é um alimento de excelente valor nutritivo devido as suas proteínas de alto valor biológico, vitaminas e ácidos graxos insaturados. De acordo com o Regulamento da Inspeção Industrial e Sanitária de Produtos de Origem Animal, o termo "pescado" compreende os peixes, crustáceos, moluscos, anfíbios, quelônios e mamíferos de água doce ou salgada usados na alimentação humana (BRASIL, 1952). Percebe-se que o consumo de pescados ainda é pouco frequente entre os brasileiros. Godoy et al. (2010) relataram que, a média nacional de consumo de pescado é de 7 a $8 \mathrm{~kg} / \mathrm{hab}$./ano, sendo muito inferior à média mundial que é de 15,8 $\mathrm{kg} / \mathrm{hab}$./ano.

Nas regiões Norte e Nordeste do Brasil, a captura de camarões dulcícolas em ambientes naturais é uma atividade tradicionalmente praticada pelos pescadores artesanais (Ramos et al., 2016). Diante desta perspectiva, o camarão da Amazônia (Macrobrachium amazonicum, Heller, 1862), é um decapoda de água doce com grande importância econômica para Amazônia (Alcântara and Kato, 2016). No estado do Pará em particular é conhecido como "camarão cascudo" ou "camarão regional" (Silva et al., 2007). Para Costa et al. (2016) é a espécie de água doce mais comumente encontrada no Brasil. Sendo endêmica da América do Sul, ocorrendo desde o Equador até a Argentina, passando pela Venezuela e estados de todas as regiões brasileiras (Amapá, Amazonas, Pará, Maranhão, Piauí, Ceará, Rio Grande do Norte, Paraíba, Pernambuco, Mato Grosso,
Paraná, Acre, Goiás e Mato Grosso do Sul) (Silva et al., 2002).

$\mathrm{Na}$ bacia Amazônica, este camarão é abundante, especialmente nos rios Solimões e Amazonas e em vários de seus afluentes (Favaretto et al., 1976). Assim, a atividade de captura e comercialização deste animal é uma importante fonte de renda para as famílias paraenses, como as que residem na mesorregião do Marajó. Localizada ao norte do estado do Pará, ao final da foz do rio Amazonas, essa ilha é a maior do Brasil e também a maior ilha fluviomarítima do mundo.

Nesta região marajoara, a captura deste crustáceo é exclusivamente artesanal, e envolve uma grande força de trabalho, geralmente de famílias que vivem ao longo dos rios. De acordo com Vieira (2003) para atividade de captura são utilizados instrumentos simples como: canoas movidas a remo ou vela (localmente conhecidas como montarias), armadilhas como os matapis entre outros apetrechos de pesca, que muitas vezes são confeccionados artesanalmente pelos próprios pescadores.

Devido sua grande abundância, ampla distribuição geográfica e importante potencial biológico, o camarão da Amazônia é a espécie nativa mais consumida pelos ribeirinhos e a mais explorada comercialmente pela pesca artesanal (Bentes et al., 2011). Dentro da cadeia produtiva desta espécie, o destino da produção inclui diversos pontos de desembarque no estado do Pará e Amapá, a partir dos quais os camarões são distribuídos por intermediários em bares, 
restaurantes, supermercados, mercados e feiras livres e aos consumidores finais de ambos estados (Lima and Santos, 2014).

A pesca é considerada uma importante fonte de alimento de elevado valor proteico de origem animal e, como atividade extrativa, responsável pela geração de emprego e renda para as comunidades litorâneas (Oliveira and Frédou, 2011). Localizado na mesorregião do Marajó, o município de Breves abriga uma tradicional feira livre municipal. Esta é considerada a maior feira livre de venda de pescado da região, tornando-se uma importante fonte de abastecimento de camarões para toda a comunidade marajoara paraense.

Devido à importância social e comercial que M. amazonicum representa, particularmente para a região Amazônica, torna-se necessário o conhecimento sobre o perfil dos vendedores e da comercialização na "Capital do Marajó", também com o intuito de direcionar futuros trabalhos para este público. Diante do exposto, objetivou-se traçar o perfil dos vendedores $\mathrm{e}$ da comercialização durante a venda do $M$. amazonicum na feira livre da cidade de Breves, região do Marajó/PA.

\section{Material e Métodos}

\section{Caracterização da área de estudo}

A pesquisa foi conduzida na Feira Livre do município de Breves, a qual pertence à Mesorregião do Marajó, estado do Pará, Brasil, à Microrregião de furos de Breves e que se encontra a $1^{\circ} 40^{\prime} 45^{\prime \prime}$ de latitude sul e $50^{\circ} 29^{\prime} 15^{\prime \prime}$ de longitude W. Gr (Figura 1). A feira acontece um prédio bem antigo, apresentando comercialização dos produtos agroextrativistas do município. Conhecido também como Mercado Municipal, sendo dividido em três partes: açougues, área de comércio de peixes e camarão, lojas para comércio de hortifrutigranjeiros, bebidas e gêneros alimentícios.

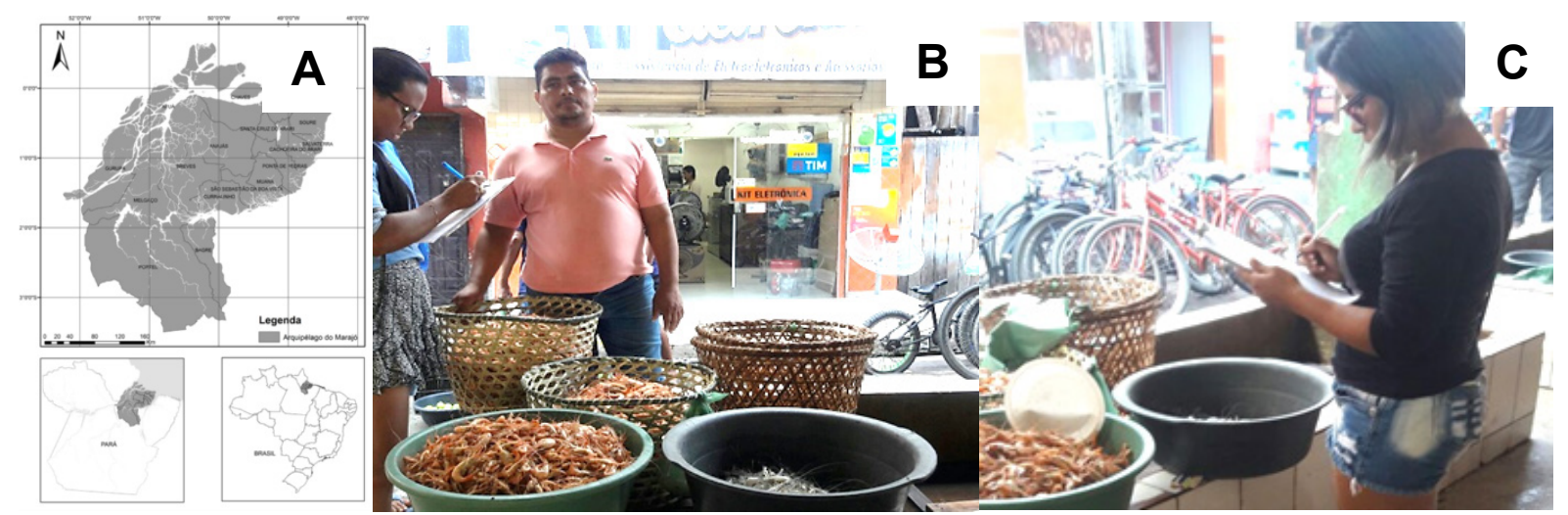

Figura 1: A - Localização do Arquipélago do Marajó, ao centro o município de Breves/PA. B e C - Entrevista realizada na Feira Livre de Breves/PA. Fonte: Anderson Mangas.

\section{Obtenção e análise de dados}

A metodologia utilizada no presente trabalho foi de natureza qualitativa, incluindo pesquisa bibliográfica, documental e de campo, sendo realizada no mês de setembro de 2016. Os vendedores foram entrevistados em seus espaços comerciais habituais, pelo período da manhã, pois é neste período em que recebem um grande número de pessoas, para vender e comprar pescados. A maioria das pessoas que frequentam a feira livre vive em pequenos povoados, comunidades e vilas madeireiras, às margens dos rios, furos e igarapés próximos à microrregião.

As entrevistas e visitações locais foram desenvolvidas pelos discentes do Curso de Criador de Peixes em Viveiros Escavados do Instituto Federal do Pará IFPA - Campus Breves. Apesar de haverem muitos vendedores no local que trabalhavam exclusivamente com a comercialização de camarão da Amazônia, apenas cinco deles aceitaram participar da presente pesquisa.

A coleta de dados foi realizada in loco, fez-se uso de um questionário com perguntas abertas, fechadas e de múltipla escolha, permitindo a obtenção de dados qualitativos e quantitativos. Desse modo, a técnica de entrevista permite obter informação imediata e corrente sobre os mais diversos assuntos de conhecimento do informante, permitindo um aprofundamento do assunto abordado. 
No que se refere ao perfil socioeconômico, foram abordadas questões sobre gênero, idade, naturalidade, estado civil, nível de escolaridade, tempo que trabalha com camarão e se esta atividade é a principal fonte de renda. Com relação ao perfil da comercialização, foi levado em consideração de como é realizada o comércio do camarão, quais os tamanhos de camarões que são vendidos, valor de comercialização por tamanho no período seco e chuvoso, qual a procedência desse crustáceo, dentre outros dados relevantes para traçar o perfil.

As informações relativas aos perfis socioeconômicos e da comercialização foram agrupadas e analisadas de forma qualitativa e quantitativa.

\section{Resultados e Discussão}

A Tabela 1 e a Figura 2 sumarizam os dados obtidos com as entrevistas realizadas junto aos vendedores de camarão na feira livre de Breves/PA. A comercialização geralmente é realizada pelo período da manhã, com o desembarque e acondicionamento em caixas de isopor e bacias plásticas com condições improvisadas e antihigiênicas.

Tabela 1. Resumo quanto ao perfil social dos vendedores de camarão da Amazônia no município de Breves/PA.

\begin{tabular}{|c|c|c|}
\hline Perfil Social (Aspecto) & Percentual & (Número de indivíduos/Total) \\
\hline Faixa etária & $\begin{array}{l}<19 \text { anos } \\
20 \text { a } 30 \text { anos } \\
31 \text { a } 40 \text { anos } \\
41 \text { a } 50 \text { anos }\end{array}$ & $\begin{array}{l}20 \%(1 / 5) \\
20 \%(1 / 5) \\
0 \%(0 / 6) \\
60 \%(3 / 5)\end{array}$ \\
\hline Sexo & $\begin{array}{l}\text { Masculino } \\
\text { Feminino }\end{array}$ & $\begin{array}{l}100 \%(5 / 5) \\
0 \%(0 / 5)\end{array}$ \\
\hline Estado civil & $\begin{array}{l}\text { Solteiro } \\
\text { Casado } \\
\text { Viúvo }\end{array}$ & $\begin{array}{c}0 \%(0 / 5) \\
80 \%(4 / 5) \\
20 \%(1 / 5)\end{array}$ \\
\hline Nível de escolaridade & $\begin{array}{l}\text { Ensino fundamental } \\
\text { incompleto } \\
\text { Ensino fundamental } \\
\text { completo } \\
\text { Ensino médio incompleto } \\
\text { Ensino médio completo } \\
\text { Ensino superior completo }\end{array}$ & $\begin{array}{c}80 \%(4 / 5) \\
0 \%(0 / 5) \\
0 \%(0 / 5) \\
20 \%(1 / 5) \\
0 \%(0 / 5) .\end{array}$ \\
\hline Quanto tempo que trabalha na venda do camarão? & $\begin{array}{l}<1 \text { Ano } \\
2-5 \text { Anos } \\
6-10 \text { Anos } \\
11-15 \text { Anos } \\
16-20 \text { Anos } \\
>21 \text { Anos }\end{array}$ & $\begin{array}{c}0 \%(0 / 5) \\
0 \%(0 / 5) \\
20 \%(1 / 5) \\
40 \%(2 / 5) \\
0 \%(0 / 5) \\
40 \%(2 / 5)\end{array}$ \\
\hline O camarão é a sua principal fonte de renda? & $\begin{array}{l}\text { Sim } \\
\text { Não }\end{array}$ & $\begin{array}{l}100 \%(5 / 5) \\
0 \%(0 / 5)\end{array}$ \\
\hline $\begin{array}{l}\text { Qual a sua renda mensal com a venda do camarão no } \\
\text { período seco? }\end{array}$ & $\begin{array}{l}<200,00 \text { reais } \\
300,00-500,00 \text { Reais } \\
600,00-800,00 \text { Reais } \\
900,00-1.000,00 \text { Reais }\end{array}$ & $\begin{array}{c}0 \%(0 / 5) \\
0 \%(0 / 5) \\
40 \%(2 / 5) \\
60 \%(3 / 5)\end{array}$ \\
\hline $\begin{array}{l}\text { Qual a sua renda mensal com a venda do camarão no } \\
\text { período chuvoso? }\end{array}$ & $\begin{array}{l}<200,00 \text { reais } \\
300,00-500,00 \text { Reais } \\
600,00-800,00 \text { Reais } \\
900,00-1.000,00 \text { Reais }\end{array}$ & $\begin{array}{c}0 \%(0 / 5) \\
100 \%(5 / 5) \\
0 \%(0 / 5) \\
0 \%(0 / 5)\end{array}$ \\
\hline
\end{tabular}

No que se refere ao perfil dos manipuladores investigados por essa entrevista se constitui de feirantes em idade avançada, na sua maioria maiores de 41 anos. Alcântara and Kato (2016) trabalhando com as boas práticas de manipulação na comercialização do camarão fresco em feiras livres de Belém/PA, enfatizam a importância de treinamentos voltados às características deste público-alvo em linguagem didática e objetiva. $\mathrm{Na}$ feira livre de Breves, evidencia-se a 
predominância do sexo masculino e homens casados, trabalhando na venda deste crustáceo.

Quando questionados sobre o local de sua origem, a maioria dos entrevistados informou ser natural de Breves/PA, sendo que apenas um é proveniente do município de Cametá/PA. Com relação ao tempo na atividade, verificou-se que $40 \%$ dos entrevistados estão na profissão entre 11 a 15 anos e acima de 21 anos. Até o presente momento, não receberam treinamento em Boas Práticas de Manipulação, e apresentaram diversas não conformidades, de acordo com a RDC 216 (BRASIL, 2004).
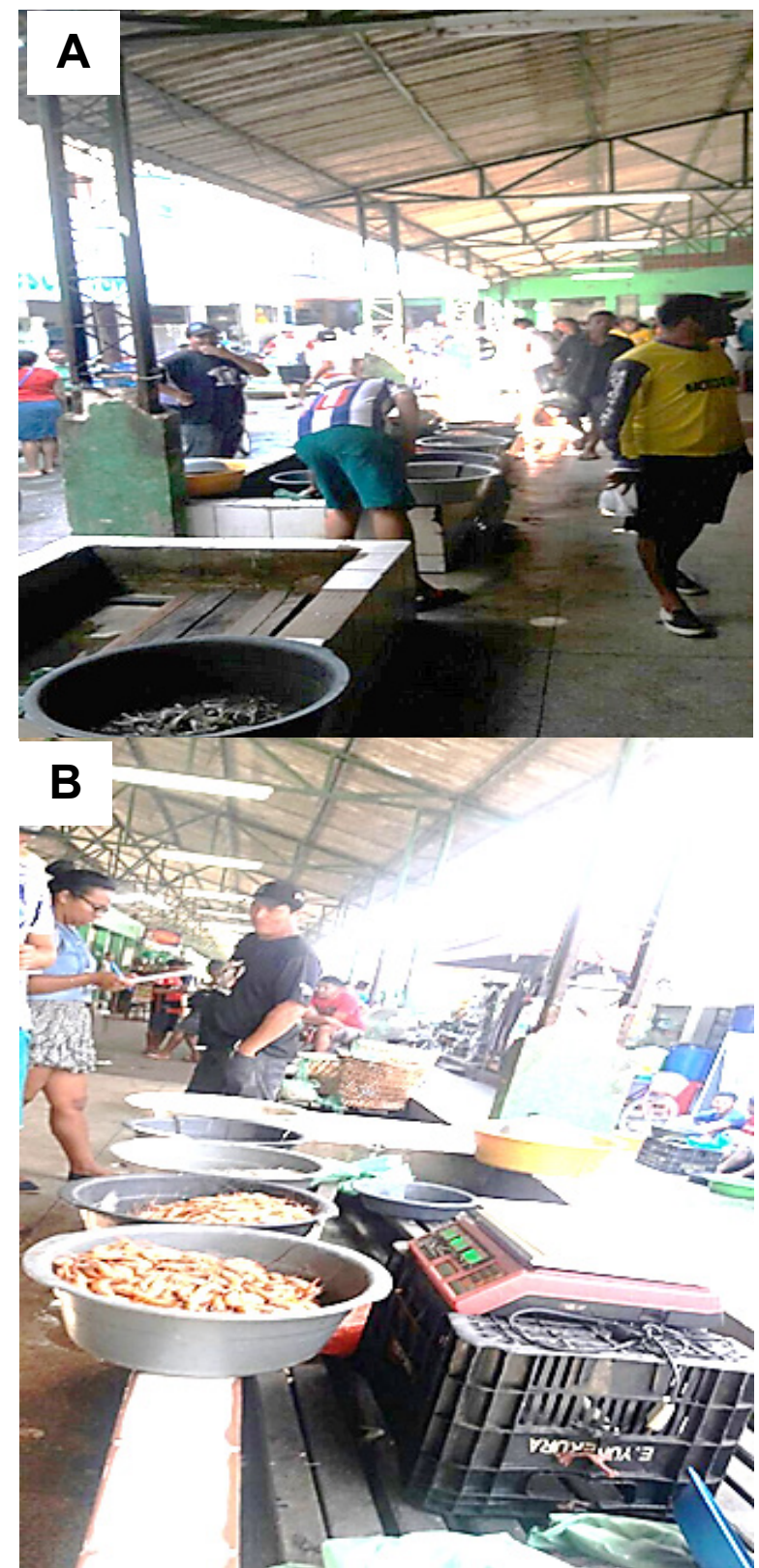

Figura 2. A e B - Imagem da infraestrutura interna da Feira Livre de Breves/PA. Fonte: Elaborado pelo Autor, 2016.
De acordo com dados pode-se constatar que são pessoas com experiência e vivência prática na área de comercialização de camarões. No entanto, lhes faltam conhecimentos técnicos para melhorar o manuseio do produto. Quanto ao nível de escolaridade, constatou-se que $80 \%$ dos entrevistados, possuem apenas o ensino fundamental incompleto e apenas um possui ensino médio completo. Pereira et al. (2011) ao analisarem a dinâmica operacional e os aspectos socioeconômicos dos trabalhadores envolvidos com o desembarque e a comercialização de pescado na área do Portinho em São Luis/MA, a grande maioria também apresentaram baixa escolaridade, corroborando com o presente estudo.

Quanto se perguntou sobre a renda mensal com a venda do camarão, muitos afirmaram que recebem valores entre $R \$ 300,00$ à $R \$ 1.000,00$ reais. Esses valores oscilam de acordo com o período da safra e entressafra da produção, que corresponde ao período seco e chuvoso, respectivamente. Na maioria das feiras livres, em Macapá e Santana, por exemplo, Lima and Santos (2014) informam que os comerciantes reportam o período entre janeiro a junho (chuvoso) como o menos produtivo, enquanto o período de julho a dezembro (seco) é considerado o mais produtivo ou de safra.

Dentre as maiores dificuldades relatadas, destaca-se a falta de infraestrutura adequada para a comercialização de alimentos. É necessário cobrar das autoridades competentes a adequação (revitalização) do espaço da feira livre. Além disso, vislumbra-se a necessidade de capacitação dos manipuladores, de modo a prevenir riscos de contaminação. Dessa forma, haverá a valorização deste setor, cuja responsabilidade é a de ofertar alimentos seguros para as famílias marajoaras, principalmente as de baixa renda.

Observou-se neste estudo que o camarão é comercializado nas seguintes formas: in natura e salgado, com casca e sem casca (Figura 3). No primeiro método de comercialização entende-se como o pescado recém-capturado, submetido ou não a refrigeração e adquirido pelo consumidor ainda em seu estado cru. Entretanto, como são bastante perecíveis, necessita estar em contato com gelo e em condições sanitárias adequadas desde sua captura, manipulação e comercialização a fim de que seja oferecido ao consumidor um produto seguro e de boa qualidade microbiológica (Abreu et al., 2008). 
$60 \%$ dos comerciantes avaliados classificam o camarão em até três classes de tamanho: pequeno, médio e grande. Os camarões considerados pequenos possuem tamanhos entre $2,0 \mathrm{~cm}$ a 5,0 $\mathrm{cm}$, os classificados como médios possuem tamanhos entre $5,0 \mathrm{~cm}$ e $8 \mathrm{~cm}$ e a partir deste são considerados como grades. Valores esses próximos dos encontrados por Lima and Santos (2014) trabalhando com aspectos econômicos e higiênico-sanitários da comercialização de camarões de água doce em feiras livres de Macapá e Santana, estado do Amapá.

Os preços médios de venda do $M$. amazonicum praticados nas feiras livre de Breves variam de acordo com o tipo de processamento, tamanho e época do ano (período seco e chuvoso). Em todos os locais de comercialização na feira os preços mostram-se mais baixos nos períodos de seca, devido ao elevado volume de oferta. Os preços neste período variam de $\mathrm{R} \$ 10,00$ a $\mathrm{R} \$ 15,00$ e R\$ 15,00 a $\mathrm{R} \$ 25,00$ reais em média para os camarões médios e grandes, respectivamente. Enquanto que no período de cheia os preços médios aumentam bastante e variam de R\$ 15,00 a $R$ \$ 20,00 reais para camarões pequenos e $\mathrm{R} \$ 20,00$ a $\mathrm{R} \$ 35,00$ para grandes.

A maior parte dos camarões que abastecem o município de Breves é proveniente do rio Ituquara, Jacaré Grande, Boca de Breves, Bagre e Afuá. A região do Afuá é a principal responsável pelo abastecimento nas feiras de Macapá e Santana (Lima and Santos, 2014). Todos os entrevistados compram o camarão diretamente dos pescadores nas ilhas e revendem para o consumidor final. Vários comerciantes informaram que compram os camarões de atravessadores aumentando os custos na cadeia produtiva.

\section{Conclusão}

Verificou-se que a venda de camarão na feira livre em Breves/PA gera emprego e renda para famílias locais, colaborando com a economia na região. Avançou-se no sentido de melhor compreender o escoamento da produção de $M$. amazonicum comercializados em feiras livres na região. Também se observou que há necessidade de treinamentos em Boas Práticas de Fabricação/Manipulação para os comerciantes da feira livre estudada.

\section{Agradecimentos}

A todos os vendedores do camarão Macrobrachium amazonicum na Feira Livre do
Município de Breves/PA pela contribuição na pesquisa realizada.

\section{Referências bibliográficas}

Abreu, M. G., Freitas, M. Q., Jesus, E. F. O., São Clemente, S. C., Franco, R. M. \& Borges, A. 2008. Caracterização sensorial e análise bacteriológica do peixe-sapo (Lophius gastrophysus) refrigerado e irradiado. Ciencia Rural, 38, 498-503.

Alcântara, G. d. L. C. \& Kato, H. C. A. 2016. Good handling practices of fresh shrimp sold in street fairs of Belém, PA, Brazil. Journal of Bioenergy and Food Science, 3, 139-148.

Bentes, B. S., Martinelli, J. M., Souza, L. S., Cavalcante, D. V., Almeida, M. C. \& Isaac, V. J. 2011. Spatial distribution of the amazon river prawn Macrobrachium Amazonicum (Heller, 1862) (Decapoda, Caridea, Palaemonidae) in two perennial creeks of an estuary on the northern coast of Brazil (Guajará Bay, Belém, Pará). Brazilian Journal of Biology, 71, 925935.

Costa, D. A. S., Martins, J. C., Silva, K. C. A., Klatau, A. G. C. M. \& Cintra, I. H. A. 2016. Seletividade do matapi nas capturas de Macrobrachium amazonicum no baixo Rio Tocantins, Amazônia, Brasil. Boletim do Instituto da Pesca, 42, 403-417.

Favaretto, L., Bogdan, A. \& Santos, E. S. 1976. Consumo de oxigênio em Macrobrachium amazonicum (Heller, 1982). Acta Amazonica, $6,449-453$.

Godoy, L. C., Franco, M. L. R. S., Franco, N. P., Silva, A. F., Assis, M. F., Souza, N. E., Matsushita, M. \& Visentainer, J. V. 2010. Sensorial analysis of soups and broths made by smoked fish carcasses meal: Its utilization to supplement school meals. Revista de Ciência e Tecnologia, 30, 86-89.

Lima, J. F. \& Santos, T. G. B. 2014. Aspectos econômicos e higiênico-sanitários da comercialização de camarões de água doce em feiras livres de Macapá e Santana, Estado do Amapá. Biota Amazônia, 4, 1-8.

Oliveira, D. M. \& Frédou, F. L. 2011. Caracterização e dinâmica espaço-temporal da atividade pesqueira na Baía de MarajóEstuário Amazônico. Arquivos de Ciência do Mar, 44, 40-53. 
Pereira, T. d. J. F., Frazão, F. B., da Silva Ferreira, L. K., Everton, F. A. \& Lima, M. d. F. V. 2011. Comercialização de pescado no portinho em São Luís, Estado do Maranhão, Brasil: uma abordagem socioeconômica dos trabalhadores. Revista Brasileira de Engenharia de Pesca, 5, $1-8$.

Ramos, A. S., Pereira, L. d. J. G., Cintra, I. H. A. \& Bentes, B. S. 2016. Etnoconhecimento de pescadores artesanais de Macrobrachium rosenbergii em campos alagados de uma região Amazônica-Brasil. Acta of Fisheries and Aquatic Resources, 4, 93-105.

Silva, K. C. A., Souza, R. A. L. \& Cintra, I. H. A. 2002. Camarão-cascudo Macrobrachium amazonicum (Heller, 1862)(Crustacea, Decapoda, Palaemonidae) no município de Vigia-Pará-Brasil. Boletim Técnico-Científico do Cepnor, 2, 41-73.

Silva, M. C. N., Frédou, F. L. \& Rosa Filho, J. S. 2007. Estudo do crescimento do camarão
Macrobrachium amazonicum (Heller, 1862) da Ilha de Combú, Belém, Estado do Pará. Amazônia, Ciência \& Desenvolvimento, 2, 85104.

Vieira, I. M. 2003. Bioecologia e pesca do camarão, Macrobrachium amazonicum (Heller, 1862) no baixo Rio Amazonas-AP. Universidade de Brasília, Brasília. Brazil.

\section{Article History:}

Received 24 December 2016

Accepted 4 February 2017

Available on line 25 February 2017

License information: This is an open-access article distributed under the terms of the Creative Commons Attribution License 4.0, which permits unrestricted use, distribution, and reproduction in any medium, provided the original work is properly cited. 